\title{
LA TOMA DE DECISIONES ORGANIZACIONALES EN UN PROCESO DE REFORMA ADMINISTRATIVA. EL GOBIERNO DIGITAL EN UN MUNICIPIO DE JALISCO, MÉXICO
}

\author{
Carlos Quintero \\ Universidad de Guadalajara \\ cep.quintero@gmail.com
}

El texto es un estudio sobre la reforma administrativa en una dependencia pública municipal. Utiliza un modelo de toma de decisiones organizacionales para el análisis del proceso de reforma. Este se diseñó desde la propuesta de Cohen, March y Olsen (2011), de toma de decisiones como bote de basura. Se desarrollan dos orientaciones de toma de decisiones, una burocrática y otra post-burocrática. Con base en una estrategia metodológica de estudio de caso se buscan relaciones de causa y efecto entre la estructura organizativa y el éxito de la reforma administrativa.

Palabras Clave: Reforma administrativa, estudios organizacionales, burocracia, postburocracia, toma de decisiones organizacionales, modelo de bote de basura.

\section{THE ORGANIZATIONAL DECISION MAKING IN AN ADMINISTRATIVE REFORM PROCESS. A E-GOVERNMENT CASE STUDY IN A MEXICAN MUNICIPALITY}

The text is a study about the administrative reform in a public municipal agency. It uses an organizational decision making model for the analysis of the reform process. It was designed from Cohen, March and Olsen's (2011) approach to decision making as a garbage can. Discusses two orientations of the decision making, a bureaucratic one and another post-bureaucratic. With the application of a methodological strategy of case study, are searched cause-effect relations between the organizational structure and the administrative reform success.

Keywords: Administrative reform, organizational studies, bureaucracy, postbureaucracy, organizational decision making, garbage can model. 
Este artículo analiza el proceso de toma de decisiones organizacionales tendientes a la reforma administrativa. Los procesos de reforma administrativa se han dado por movimientos que ejercen presión en momentos y a ritmos diferenciados. También en espacios y lugares distintos del sistema político-administrativo; pero con un objeto de atención más o menos constante, los gobiernos y sus administraciones. La reforma administrativa se ha dado por movimientos que ejercen presión en momentos y a ritmos diferenciados. También en espacios y lugares distintos del sistema político-administrativo; pero con un objeto de atención más o menos constante, los gobiernos y sus administraciones.

Por esta razón, el presente trabajo se propone examinar si características organizacionales vinculadas a la Post-Burocracia son más, o menos, importantes que aquellas que se asocian con la burocracia tradicional para lograr la reforma administrativa. Para lograr esto se elabora un modelo de análisis basado en el trabajo de Cohen, March y Olsen: "El bote de basura como modelo de elección organizacional" (2011). Utilizando las variables estructurales del modelo, se propone un modelo original. Este puede adecuarse a patrones de toma de decisiones organizacionales diferentes. Aquí propongo hacia dos orientaciones: por un lado la orientación a la Post-Burocracia y por el otro, a la Administración Pública Tradicional, o burocrática. Con este modelo se estudió un proceso de reforma administrativa, en una dependencia del Municipio de Zapopan, en el estado de Jalisco, México. El proceso de reforma fue el de "Zapopan Ciudad Digital". Una estrategia de modernización administrativa basada en el uso de tecnologías de información y comunicaciones. La respuesta del análisis sugiere que el éxito de la reforma administrativa se dio en un proceso orientado hacia la Administración Pública Tradicional frente a la orientación a la Post-Burocracia. Es decir, los rasgos estructurales vinculados con la primera orientación fueron los más frecuentes en este caso de reforma, que los rasgos estructurales de la segunda orientación.

En la primera parte se hace una problematización amplia sobre los cuerpos teóricos que conforman el estudio: toma de decisiones, reforma administrativa y sus fuentes, administración pública y teoría organizacional. Sigue con el modelo de análisis que se diseñó para el estudio. La tercera parte trata las cuestiones metodológicas. Los dos últimos apartados cierran con análisis de los resultados y las conclusiones del estudio. 


\section{i. Administración Pública Tradicional y la Reforma Administrativa}

Lynn (2001) demuestra que es una falacia el adjetivar como "tradicional" a la administración pública burocrática, a la vez de categorizarla como la más baja de las formas de acción pública; sin embargo, para llamarle de algún modo a la percepción monolítica, piramidal, autorreferente y estática que se tiene de las organizaciones públicas, decirle "tradicional" no queda de más. La Administración Pública Tradicional, con todo, fue un planteamiento sumamente útil, si se le entiende como burocracia en el sentido weberiano del término (Weber, 1964).

La Administración Pública Tradicional, con su expresión histórica concreta conocida como organización burocrática, se ha definido basada en sus características estructurales (Heady, 2000). De manera concisa, se muestran seis rasgos básicos (Hall, 1962):

1. Jerarquía de autoridad bien definida

2. División del trabajo basada en la especialización funcional

3. Sistema de normas relativas a los derechos y obligaciones de los funcionarios que desempeñan los distintos cargos

4. Sistema de procedimientos relativo a las relaciones de trabajo

5. Impersonalidad de las relaciones interpersonales

6. Selección para empleos y ascensos basada en la competencia técnica.

Dicha lista de rasgos se repite en casi todos los autores al hablar de burocracias. El padre de la noción en esta acepción, Max Weber, trató a la forma de organización burocrática, en tanto tipo ideal, como el modelo socialmente imperante, en una era de racionalidad instrumental, es decir, de arreglo medios-fines (Weber, 1964). A esta expresión de la racionalidad Weber la encuentra como la más apta para el momento histórico en que se sitúa; la única capaz de lograr los resultados que tanto el Estado como la Sociedad requerían. Se destaca que el mismo autor observa que este tipo de organización no es privativa del Estado, sino también del sector privado. Como modelo ordenador, paradigmático, nunca se presentó por completo en la realidad, pero sí orientó las acciones de los gobiernos, las empresas y la sociedad dentro de los esquemas organizativos que planteó. 
Se sigue de la lista de rasgos de las burocracias (Hall, 1962) que la Administración Pública Tradicional no considera la toma de decisiones como algo abierto. Los distintos puntos fuerzan a un proceso de toma de decisiones basado en normas previamente establecidas, y que, por tanto, no pueden ser contestadas o rebatidas por los miembros de la organización. Estos últimos más bien tratan de ejecutar una decisión anteriormente establecida. Pudiendo llegar a un extremo disfuncional (Merton, 1964), en donde se desplazan las metas sustantivas a la organización por aquellas que se entenderían por procedimentales (Garvía, 1993), la forma de organización burocrática lleva a entender el proceso de toma de decisiones como algo que no debiera ir más allá de una rutina. Dicho enfoque es el que combaten la nueva gestión pública, la Post-burocracia y ahora la Gobernanza. Con ojos contemporáneos, dicho modelo burocrático se encuentra desfasado, pero todavía presente. Más importante aún, este es el modelo sobre, y contra, el que se ha elaborado la discusión en cuanto a la toma de decisiones organizacionales, reforma administrativa, nueva gestión pública, Post-Burocracia y Gobernanza. En los siguientes sub-apartados se discute sobre ello.

Por otra parte, cuando hablamos de reforma administrativa debemos recordar que su significado es algo muy escurridizo. Distintos autores hablan de reforma administrativa de muy variadas formas. Hay quienes la consideran sólo como algo que se sitúa en lo concreto y cotidiano de las organizaciones (Nuevos sistemas contables, por ejemplo) hasta cambios que afectan al Estado y el sistema político en pleno (la rendición de cuentas o el cambio en la relación entre los Poderes del Estado). Que puede ser esporádico o una constante (Brunsson, 2009). Existen, empero, algunos elementos comunes a las definiciones y perspectivas sobre la reforma. Siguiendo a Dussauge (2009), aquí se entenderá que una reforma administrativa tiene las siguientes propiedades:

a) la presencia de un esfuerzo deliberado, intencional;

b) que busca alterar procesos, estructuras, diseños organizacionales;

c) para mejorar, ajustar, modernizar, elevar la calidad de la administración pública y sus componentes.

Las propiedades de las que habla el autor son consistentes con una ya clásica en el estudio de la reforma administrativa, la de Pollitt y Bouckaert (2011:8): 
"podríamos decir que la reforma de la gestión pública consiste en cambios deliberados a las estructuras y los procesos de las organizaciones del sector público con el objetivo de hacer que (en algún sentido) se manejen mejor".

Tanto la definición de Pollitt y Bouckaert como las propiedades que identifica Dussauge, pueden incluir a muchos tipos de reforma administrativa. Por ello es conveniente delimitar más su sentido, y la importancia para el tema que compete. En primer lugar, la reforma administrativa es una constante gubernamental; un proceso en el que está inmerso el sector público de manera perenne (Laufer \& Burlaud, 1988). Cabrero (1997) señala que la reforma puede tener distintos niveles de profundidad; el análisis de este autor problematiza el espacio y nivel de la reforma. Aunque no discurre para grados más profundos de reforma, como sería el caso de la Reforma del Estado en su nivel político-constitucional, sí abre la puerta a estudiar la reforma como algo administrativo y sin miras tan ambiciosas.

Debido a las reformas administrativas contemporáneas, más o menos exitosas, más o menos extensas, más o menos profundas, las organizaciones gubernamentales han cambiado tanto su estructura como su desempeño en más de una forma. Por ello la agenda, limitada, de reforma administrativa se centró en la que se propuso desde la nueva gestión pública (Pollitt \& Bouckaert, 2011; Ferlie, Lynn, $\&$ Pollitt, 2007). Aquí se considera que la reforma administrativa sucede en el nivel organizativo del gobierno. Encontrándose que se articula al sucederse las propiedades de un fenómeno organizacional (este último concepto presentado en un sentido muy amplio), donde intencionalmente se busca alterar alguna dimensión, elemento, característica o proceso de la organización, para lograr una mejora deseable por algún actor interesado y vinculado a la misma administración pública en donde ocurre la reforma.

\section{SOBRE POST-BUROCRACIA}

Uno de los movimientos teóricos y prácticos que comienzan a trabajar la gestión pública y la teoría organizacional, encuentra cobijo bajo una etiqueta: la Post-Burocracia. Si bien la nueva gestión pública considera a las formaciones organizacionales post-burocráticas (Osborne \& Gaebler, 1992) como parte natural de su agenda, la discusión previa deja entrever algunas salvedades y tensiones. Entre ellas: no son organizaciones que trabajen colaborativamente, que traten temas 
distintos o provean más de un par de servicios. Considerando esto, hay movimientos en marcha, también de corte reformista, que buscan resolver las problemáticas dejadas por la nueva gestión pública (Christensen \& Laegrid, 2006). Las causas del auge de las organizaciones post-burocráticas, así como su estudio, son varias y se comparten con las de la nueva gestión pública, pero incluyen críticas hechas a la última, revisiones de problemáticas viejas y nuevas conceptualizaciones. Tiene como principal intención el considerar a los resultados gubernamentales como un conjunto agregado de la acción coordinada e interactiva hacia dentro de los gobiernos y hacia la sociedad ${ }^{1}$ (Aguilar Villanueva, 2011a y 2011b).

La noción de organización post-burocrática cobija a las organizaciones flexibles, descentralizadas, abiertas y, muy especialmente, más responsables y con capacidad de gestión del conocimiento (Christensen \& Laegrid, 2012; Johnson, Wood, Brewster, $\&$ Brookes, 2009). Parte de la discusión sobre organizaciones post-burocráticas es que las reformas tendientes a introducirlas en el sector público deben convivir con reformas previas. En palabras de Christensen y Laegrid (2009) las organizaciones comienzan a 'hibridarse'. Esto tiene implicaciones teóricas y prácticas. Dirige la atención a identificar factores relevantes a la toma de decisiones organizacionales, así como de dudar de opciones de investigación que atribuyan todo el éxito o el fracaso de una reforma a factores únicos. Esto disminuye la claridad conceptual del tema, pues puede haber énfasis en cuestiones como la confianza hacia el interior de la organización como mecanismo de reforma post-burocrática (Grey \& Garsten, 2001) o explicaciones que achacan el cambio a la infraestructura tecnológica y económica, como da cuenta la explicación de Castells (1996).

Haciéndose difícil un estudio con muestras grandes y representativas, conviene en la presente etapa la realización de estudios más mesurados. Esto ayudará a ganar claridad conceptual a la noción de organizaciones post-burocráticas (Bolin \& Härenstam, 2008).

Con la breve discusión expuesta, aquí se entiende a la organización postburocrática como una organización con las siguientes características:

1. Una jerarquía de autoridad flexible y adaptable

1 Esta idea y su desarrollo la agradezco al Dr. Aguilar Villanueva. 
2. Una división del trabajo basada en la colaboración intra e interorganizacional

3. Un sistema de responsabilidad eficaz

4. Un sistema de trabajo pro-activo

5. La personalización y achicamiento de las relaciones entre los miembros de la organización y con agentes externos

6. El uso del conocimiento para la producción y co-producción de bienes y servicios de manera eficiente.

La definición que utilizaría para el análisis viene de la integración de los rasgos expuestos, pero en una clave organizacional.

\section{TEORÍA ORGANIZACIONAL}

La burocracia como la presentó Weber (1964), el inicio de la administración científica con Fayol (1961) y Taylor (2000), la incorporación de las relaciones humanas dentro de las organizaciones con Mayo, el observar las relaciones de dependencia (Pfeffer, 1981), las categorías de March, Cohen y Olsen en su "modelo de bote de basura” (2011), el concepto de racionalidad limitada de Simon (1997), el foco de atención en las restricciones institucionales planteado por Powell y Di Maggio (1991), por mencionar contribuciones, fueron bloques básicos sobre los cuales se ha ido construyendo la teoría organizacional moderna. Hacer un repaso de todos ellos no es el objeto de este escrito. Se toma una elección sustancial y, sobre ella, propongo el modelo de análisis. Dicha elección corresponde a la teoría organizacional de la escuela de Simon y sus deudores, Cohen, March y Olsen. Mínimamente, Simon (1997) propone que una organización:

"refiere al complejo diseño de comunicaciones y demás relaciones existentes dentro de un grupo de seres humanos". Continúa con que "Este diseño proporciona a cada miembro del grupo una gran parte de la información, de los supuestos, objetivos y actitudes que entran en sus decisiones, y también una serie de expectativas fijas y comprensibles de lo que los demás miembros del grupo están haciendo y de cómo reaccionarán ante lo que él diga y haga”. 
Mientras que una postura de lo que es una organización, con un corte racionalista más radical, puede considerarla como actores colectivos, "definidos por su capacidad de tomar decisiones de manera centralizada" (Elster, 2007), la postura de Simon y March, se mantiene consistente con la agenda iniciada por el primero: "Las organizaciones son sistemas de acción coordinada entre individuos y grupos cuyas preferencias, información, intereses o conocimiento difieren" (Simon \& March, 1993). De forma básica, una organización es, sí, un agregado de toma de decisiones, donde se coordinan actores y se divide el trabajo para lograr unos ciertos fines (Mintzberg, 2005). Con este objeto, es importante recurrir a alguna propuesta que pueda ser utilizada para el estudio de las organizaciones públicas desde una perspectiva burocrática o post-burocrática.

Las organizaciones públicas no son espacios racionales en un sentido puramente administrativo; son espacios donde convergen individuos sin metas claras, donde el conocimiento de los medios con los cuales alcanzarlas es ambiguo, la incertidumbre que generan las consecuencias es alta y los problemas están pobremente definidos. Pero las organizaciones públicas sí pueden ser razonables. Ofrecen capacidades de procesamiento de información y trabajo superiores a la que pudieran ofrecer los individuos en solitario; parafraseando a Simon, las organizaciones pueden pensar en paralelo mientras que los individuos sólo lo hacen en serie. Para el Estado, esto es una función de su estructura decisional y el grado de descentralización (Ayala Espino, 2000). Aquí se refiere a la discusión de Crozier y Friedberg (1990) sobre las regularidades en el comportamiento de los actores en las organizaciones y, entonces, la racionalidad que se puede observar. Donde desde el estudio posterior de las estrategias llevadas a cabo, es posible inferir la racionalidad de los actores. Esto a pesar de que a priori las acciones no contribuyan eficientemente, o en lo absoluto, a los objetivos formales de la organización.

\section{TOMA DE DECISIONES ORGANIZACIONALES}

A efectos del estudio, se define como toma de decisiones al proceso a través del cual se generan elecciones, esto por parte de actores organizacionales. El proceso de toma de decisiones es concerniente a temas específicos. De las elecciones llevadas a cabo, se hacen derivar acciones más o menos vinculantes para la organización 
y el conjunto de actores que en ella participan. De acuerdo a Elster (1991), la acción racional consta de dos conjuntos de restricciones que aparecen durante la decisión: el conjunto de restricciones materiales y el conjunto valorativo de la decisión. El primero consiste en la frontera de posibilidades que, físicamente, sostiene al proceso decisorio, mientras que el segundo conjunto refiere a lo subjetivo de la decisión. Esto encuentra eco en Vickers (1995), quien presenta ambos conjuntos como los límites donde puede suceder la decisión.

Canónicamente se considera que en un proceso de toma de decisiones hay un momento ex ante en el que:

1. Se define un tema,

2. Se reúnen datos e información sobre el mismo,

3. Se evalúan distintas opciones únicamente por los actores organizacionales que ocupan posiciones directivas, $y$

4. Se decide en función de los fines optimizadores del tomador de decisiones (Cyert y March, 1965; Simon, 1989).

La decisión en sí misma es la elección concreta que se toma. Al siguiente momento, el ex post, le concierne asegurar que la decisión tomada se cumpla. Este proceso es, primero, más complejo y, segundo, más ambiguo de lo que se supone. No es cierto que la toma de decisiones sea lineal, completa y segura (Cyert y March, 1965; Simon y March, 1993, Simon, 1997; Culebro, 2003), ni siquiera que los que se supone pueden y deben decidir, decidan de manera libre y sin constricciones dentro de su conjunto de posibilidades materiales (Crozier, 1974).

Se considera que la toma de decisiones para provocar la reforma administrativa, es algo recurrente, que no ofrece certezas de cambio e innovación inmediata y sinóptica (Brunsson \& Olsen, 2007) empero, va insertando cambios graduales, a manera del proceso de sedimentación de los suelos, en los contextos organizacionales e institucionales en que ocurre (Christensen, Lægreid, Roness \& Arne Røvik, 2007).

\subsection{LA TOMA DE DECISIONES COMO "BOTE DE BASURA"}

Considerando que la toma de decisiones, y en particular la organizacional, puede sostenerse basada en diversos modelos (por ejemplo Allison y Zelikow, 1999), aquí 
se opta por uno en particular. El modelo de toma de decisiones organizacionales como bote de basura. Con este modelo se plantea caracterizar y analizar la reforma administrativa en cuestión. Aquí se hace una breve recapitulación del modelo. Primero, se presentó en un artículo para la revista "Administrative Science Quarterly” por Michael Cohen, James March y Johan Olsen en la década de los setenta del siglo pasado, consolidándose como una propuesta original y de amplio impacto en la literatura organizacional. El modelo se sitúa dentro de una corriente de pensamiento social y organizacional con orígenes, ya para este momento, lejanos. De manera un tanto arriesgada, el modelo de bote de basura, así como sus autores, pueden incluirse en la escuela iniciada por Herbert A. Simon y su texto fundacional, "Administrative Behavior. A Study of DecisionMaking Processes in Administrative Organizations" (1997).

La propuesta teórica de Cohen et al., no busca una prescripción de tipo "bestway". Es decir, no es una aportación gerencialista. A lo más, los autores proponen una forma de entender los procesos decisionales dentro de las organizaciones. Y desde ahí, se pueden inferir mejores cursos de acción. Tampoco niegan la racionalidad de los individuos o de sus organizaciones para orientarse a fines, pero atemperan el proceso decisional con la idea del bote de basura y de anarquías organizadas.

Curiosamente, el modelo de bote de basura ha tenido menos aplicaciones en la teoría organizacional que en otras disciplinas; digamos, en el análisis de políticas públicas. La teoría de corrientes de políticas de Kingdon (1997) descansa en este modelo organizacional. Así también los estudios de Barzelay (2003) en cuanto a metodología de gestión pública, son deudores indirectos de March et al. A su vez, son pocos los estudios empíricos que utilizan el marco de análisis de manera sistemática (Zahariadis, 2007).

¿En qué consiste el modelo de bote de basura? Olsen (2001), al hacer una revisión del original, dice que el artículo sólo presentaba un modelo, que trataba de explicar la toma de decisiones en organizaciones complejas. El original puede dividirse en dos partes. La primera expone la teoría del bote de basura para anarquías organizacionales. La segunda, desarrolla la simulación computacional que se corrió en Bergen, Noruega. En primer lugar, el texto explica cuatro corrientes que fluyen a través de las organizaciones: de problemas, soluciones, participantes y oportunidades de elección. Los autores definen problemas como "lo que preocupe 
a personas dentro y fuera de la organización"; soluciones como el "producto de alguien"; que los participantes "vienen y van" y que como "cada entrada es una salida en algún otro lugar, la distribución de 'entradas' depende de los atributos de la elección que se deja de lado tanto como en los atributos de la nueva elección”. Por último, las oportunidades de elección son "ocasiones cuando se espera que una organización produzca un comportamiento que pueda ser llamado decisión" (Cohen, March, \& Olsen, 2011).

Dentro de la parte conceptual, los autores muestran cómo es que la estructura organizacional afecta los productos de la hechura de decisiones en un bote de basura: a través del patrón de tiempo en que llegan los problemas, soluciones y hacedores de decisiones; determinando la localización de energía por parte de los participantes potenciales en la decisión; estableciendo enlaces entre las diferentes corrientes. Los parámetros estructurales que presentan son los siguientes: "Número de entradas para elecciones", "Carga neta de energía en la organización”, "Estructura de acceso de la organización", "La estructura de decisión de la organización” y "La distribución de la energía entre los hacedores de decisión en la organización". A continuación se presenta una breve descripción de cada uno de los parámetros.

Tabla 1: Variables Estructurales del Modelo de Bote de Basura

\begin{tabular}{l|l}
\hline Variables Estructurales del Modelo de Bote de Basura \\
\hline Número de entradas para elecciones & $\begin{array}{l}\text { Es el patrón de tiempo en que entran las elecciones } \\
\text { dentro del proceso }\end{array}$ \\
\hline Carga neta de energía en la organización & $\begin{array}{l}\text { Es la diferencia entre el total de energía de los par- } \\
\text { ticipantes y lo necesario para resolver un problema }\end{array}$ \\
\hline Estructura de acceso de la organización & Es la relación entre los problemas y las elecciones \\
\hline La estructura de decisión de la organización & $\begin{array}{l}\text { La relación entre los hacedores de decisiones y las } \\
\text { elecciones. }\end{array}$ \\
\hline $\begin{array}{l}\text { La distribución de la energía entre los hace- } \\
\text { dores de decisión en la organización }\end{array}$ & $\begin{array}{l}\text { Refleja las variaciones en el tiempo invertido en } \\
\text { problemas organizacionales por distintos hacedores } \\
\text { de decisiones. }\end{array}$ \\
\hline
\end{tabular}

Fuente: Elaboración propia con base a Cohen et al. (2011). 
Dichos parámetros son estructurales, inherentes, a las organizaciones. Se presentan en todas y cada una. Sin embargo, el tratamiento y productos que generan, varía en cada caso concreto. Los autores, Cohen et al., concluyen que la virtud del estudio es que permite entender los procesos de bote de basura. Mientras que en algunos casos pudiera eliminarse el proceso de bote de basura, no siempre es posible o deseable. Así, dejan abierta la agenda de investigación para el diseño y gestión de las organizaciones.

\section{Ilustración 1: diagrama del modelo de bote de basura}

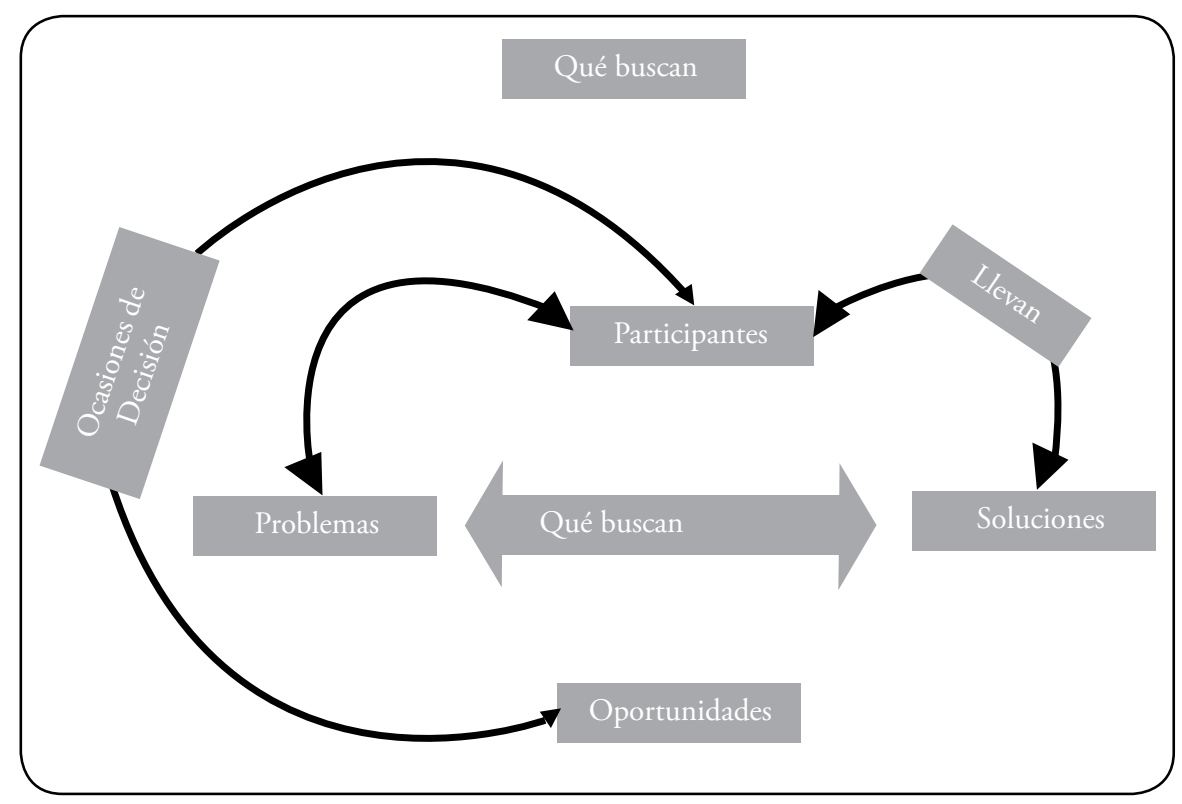

Fuente: elaboración propia con base en Cohen, March y Olsen (2011).

La literatura sobre toma de decisiones considera antes un proceso decisorio, basado en principios de individualismo metodológico, que una estructura de la decisión (Resnik, 1998)(Parsons, 2007). Sin embargo, recurriendo a la noción de configuración estructural de Mintzberg (2005) y a la propuesta sobre toma de decisiones del modelo de cesto de basura de Cohen et al. (2011), se puede construir la noción de estructura de toma de decisiones. Del primer autor, se recupera el hecho de que una organización presenta una cierta estructura contingente. Hay elementos, como el tiempo o el tamaño, que constriñen las 
distintas posibilidades de cómo una organización puede ser (Culebro, 2003). Esto abre un horizonte heurístico y permite caracterizar a la organización como una estructura de toma de decisiones (Luhmann, 1997), y ubicar, con carácter de estructural, a los parámetros que Cohen, March y Olsen proponen.

\section{Modelo de AnÁlisis}

Habiendo presentado la discusión sobre la toma de decisiones organizacionales, se propone un modelo propio. El presente modelo, que se basa en la toma de decisiones como bote de basura para construir la estructura analítica, soporta contenidos que señalan dos extremos: el de la toma de decisiones burocrática y la toma de decisiones post-burocrática. A continuación se presenta el modelo y la metodología con la que se explota.

Se considera que la estructura de decisión está compuesta por los siguientes parámetros:

- Acceso de participantes en el proceso de toma de decisiones;

- Corresponsabilidad de los participantes en la toma de decisiones;

- Formalización del proceso de toma de decisiones;

- Dispersión de la atención sobre temas en el proceso de toma de decisiones; $\mathrm{y}$,

- Causalidad de la toma de decisiones.

Se parte de que cada uno de los parámetros se exhibe en cualquier proceso decisorio, de cualquier organización. Esto siendo cierto tanto para la orientación hacia la Administración Pública Tradicional como la orientación hacia la postburocrática. Esto ocurre pues la estructura de decisión no está puesta a prueba; existe, de una u otra manera, en cualquier organización. Siempre existirá la división y coordinación de trabajo en cualquier organización, el cómo se realice y coordine dicha división es particular a la organización y su coyuntura (Mintzberg, 2005) (Crozier, 1974). Así, lo que aquí llamo "Estructura de decisión”, conformado por los cinco parámetros presentados, tiene un carácter apriorístico, teórico.

A continuación se explica brevemente cada parámetro: 
Tabla 2: Parámetros del Modelo de Estructura Decisional

\begin{tabular}{l|l}
\hline Parámetro & Definición \\
\hline Acceso de Participantes & $\begin{array}{l}\text { Corresponde al patrón de actores que intervienen } \\
\text { en el proceso de toma de decisiones sobre un tema } \\
\text { específico. }\end{array}$ \\
\hline $\begin{array}{l}\text { Corresponsabilidad de los participantes en } \\
\text { la toma de decisiones }\end{array}$ & $\begin{array}{l}\text { Considera la participación, creíble, de un actor } \\
\text { dentro de un proceso decisorio. }\end{array}$ \\
\hline $\begin{array}{l}\text { Formalización del proceso de toma de } \\
\text { decisiones }\end{array}$ & $\begin{array}{l}\text { El proceso decisorio específico se realiza bajo un } \\
\text { marco normativo establecido. }\end{array}$ \\
\hline $\begin{array}{l}\text { Dispersión de la atención sobre temas en el } \\
\text { proceso de toma de decisiones }\end{array}$ & $\begin{array}{l}\text { La cantidad de temas que se recuperan y atienden } \\
\text { durante el proceso decisorio. }\end{array}$ \\
\hline Causalidad en la toma de decisiones & $\begin{array}{l}\text { Refiere a la vinculación causal, explícita, que se } \\
\text { le adjudica a las acciones respecto a las metas y } \\
\text { objetivos de la decisión. }\end{array}$ \\
\hline
\end{tabular}

Fuente: Elaboración propia.

Para el presente estudio, cada uno de los parámetros puede entenderse dentro de un continuo. En un extremo se encontraría lo que se plantea como una organización post-burocrática y en el otro, la organización burocrática. En dicho continuo, los parámetros presentan características distintas. Así, se podrá vincular con el éxito de una reforma administrativa. En los siguientes párrafos se desagregan y explican las variables de cada uno de los parámetros de la estructura de decisión. Se presentan en cuanto a la orientación hacia la Post-Burocracia y hacia la Administración Pública Tradicional.

\section{a) Acceso de Participantes}

El primer elemento estructural corresponde a la forma en que los participantes en la organización entran en un determinado proceso de toma de decisiones. En este sentido, la relación de participantes corresponde en parte al número absoluto de personas. Pero también sobre si los participantes en el proceso decisional incluyen a personal operativo y/o gerencial. Incluyéndose también si intervienen stake holders externos a la organización durante la toma de decisión. Esta variable se deriva desde lo que Cohen, March y Olsen llamaron "Número de entradas para elecciones". 


\section{Tabla 3: Parámetro Estructura de Acceso de Participantes}

\begin{tabular}{l|l}
\hline Post-Burocracia & Admón. Pública Tradicional \\
\hline $\begin{array}{l}\text { Regularmente participan actores de distintos } \\
\text { niveles organizacionales en el proceso de toma de } \\
\text { decisiones sobre un tema específico }\end{array}$ & $\begin{array}{l}\text { Regularmente sólo participan actores del } \\
\text { mismo nivel organizacional en el proceso de } \\
\text { toma de decisiones sobre un tema específico }\end{array}$ \\
\hline
\end{tabular}

Fuente: Elaboración Propia.

La variable se sitúa completamente en el espacio de la Post-Burocracia cuando, en una decisión, participan actores internos, externos, de nivel directivo-gerencial y operativo. Se situará completamente en la Administración Pública Tradicional, cuando en la decisión sólo participe un tipo de actor e interno. A efectos operativos se utilizan cuatro posibles tipos de actores: Internos, externos, directivos y nodirectivos. Contando en el último tipo tanto a actores gerenciales como a operativos.

\section{Tabla 4: Parámetro Estructura de Acceso de Participantes}

\begin{tabular}{l|l|l|l}
\hline Post-Burocracia & $\begin{array}{l}\text { Relativamente orientada a } \\
\text { la Post-Burocracia }\end{array}$ & $\begin{array}{l}\text { Re la tiv a m e n t e } \\
\text { Orientada a la APT }\end{array}$ & $\begin{array}{l}\text { Administración Pública } \\
\text { Tradicional }\end{array}$ \\
\hline $\begin{array}{l}\text { Cuatro tipos de } \\
\text { actores }\end{array}$ & Tres tipos de actores & Dos tipos de actores & Un tipo de actor \\
\hline
\end{tabular}

Fuente: Elaboración Propia.

\section{b) Corresponsabilidad de los participantes en la toma de decisiones}

Se tratará, con base en la noción de carga de energía de la organización, a los recursos que ponen en juego los actores organizacionales en una decisión dada. Así, la variable es de corresponsabilidad por el necesario envolvimiento de los actores al ofrecer recursos en una decisión. Esto distingue a aquellos actores que participan de manera tangencial en el proceso de toma de decisiones, frente a aquellos actores que importan para la decisión. 
Tabla 5: Parámetro Corresponsabilidad en el proceso de toma de decisiones

\begin{tabular}{l|l}
\hline Post-Burocracia & Admón. Pública Tradicional \\
\hline $\begin{array}{l}\text { Normalmente ofrecen recursos propios de de } \\
\text { manera creíble para la toma de decisiones }\end{array}$ & $\begin{array}{l}\text { Normalmente no ofrecen recursos propios de } \\
\text { manera creíble para la toma de decisiones. }\end{array}$ \\
\hline
\end{tabular}

Fuente: Elaboración Propia.

Se utiliza la clasificación de instrumentos de política de Hood y Margetts (2007) para identificar los recursos que ponen en juego durante una decisión. La clasificación comprende instrumentos de nodalidad, tesoro, organización y jurídicos. Los instrumentos de nodalidad son propios a la información, conocimiento y comunicación entre las organizaciones y sus públicos. Los de tesoro pueden reducirse a lo financiero, pero también puede considerar recursos en especie. Los de organización, son recursos que competen a la sustitución directa de trabajo por otro recurso. Los últimos, de tipo jurídico, son recursos de habilitación o prohibición legal.

Visto lo anterior, se propone como indicador que si una mayoría de los actores organizacionales ofrecen regularmente recursos de algún tipo, de manera creíble, situarían a la organización en el extremo de Post-Burocracia. Si no se ofrecen recursos, se situarán en el polo de Administración Pública Tradicional. Si se juzgara, por ejemplo, que los actores organizacionales no ofrecieran ningún tipo de recurso, salvo jurídicos. ¿No pudiera considerarse que se encuentren en situación de Post-Burocracia? En este caso no. Se promediará el grado de compromiso en el ofrecimiento de recursos. El promedio de los cuatro tipos de recursos, en forma de corresponsabilidad decisional, llevarán a la variable general de "Corresponsabilidad de la Toma de decisiones".

Mientras más se acerquen al polo de Post-Burocracia, más alta sería su puntuación. Se asignan cuatro puntos a este polo y uno al extremo contrario. Si una organización se encuentra con un promedio de valor cuatro, se ubicaría en el polo de la Post-Burocracia. Si tiene un promedio de uno, en el polo de la Administración Pública Tradicional. 


\section{Tabla 6: Desagregación de las Variables propias del Parámetro Corresponsabilidad en el Proceso de Toma de Decisiones}

\begin{tabular}{|c|c|c|c|}
\hline Post-Burocracia & $\begin{array}{l}\text { Relativamente } \\
\text { orientada a la } \\
\text { Post-Burocracia }\end{array}$ & $\begin{array}{l}\text { Relativamente } \\
\text { Orientada a la APT }\end{array}$ & $\begin{array}{l}\text { Administración Pública } \\
\text { Tradicional }\end{array}$ \\
\hline $\begin{array}{l}\text { Muchos actores ofrecen } \\
\text { recursos: Financieros; } \\
\text { Organizacionales; } \\
\text { Jurídicos y de Nodalidad }\end{array}$ & $\begin{array}{l}\text { Algunos actores } \\
\text { ofrecen recursos: } \\
\text { Financieros; } \\
\text { Organizacionales; } \\
\text { Jurídicos y de } \\
\text { Nodalidad }\end{array}$ & $\begin{array}{l}\text { Pocos actores } \\
\text { ofrecen recursos: } \\
\text { Financieros; } \\
\text { Organizacionales; } \\
\text { Jurídicos y de } \\
\text { Nodalidad }\end{array}$ & $\begin{array}{l}\text { No se ofrecen } \\
\text { recursos: Financieros; } \\
\text { Organizacionales; } \\
\text { Jurídicos y de Nodalidad }\end{array}$ \\
\hline
\end{tabular}

Fuente: Elaboración Propia.

c) Formalización del proceso de toma de decisiones

Con base en la noción de "Estructura de acceso de la organización" del modelo de bote de basura, se plantea la formalización del proceso de toma de decisiones como una categoría equivalente. De manera mínima, se puede observar que, si bien el marco normativo de las organizaciones puede parecer poco relevante, sí sanciona la entrada y salida de actores en los procesos decisionales. Esto permite elaborar sobre cómo entran y salen los actores en las organizaciones públicas.

Se encuentra a la sanción jurídica de los actores como apropiada, frente a otras variables como el ratio de rotación de actores, tal como lo puedan percibir los entrevistados, por la siguiente razón: la definición exhaustiva de responsabilidades permite vislumbrar el mínimo de actores legítimos en un proceso decisorio. Regulaciones que habilitan a cualquier afectado por una reforma regulatoria a elevar una queja, o, en extremo, la posibilidad de introducir juicios de amparo ante casi cualquier hecho administrativo, nos hace considerar esta dimensión como una que, de manera aproximada, visualiza a la estructura de participantes. En este estudio se parte de que una organización pública, en una situación de post-burocracia, consiente que la definición de actores que pueden participar en el proceso decisorio es enunciativa, pero no exhaustiva. Abre la posibilidad de que participen más actores involucrados en la toma de decisiones. Establece situaciones en las cuales se deben convocar a actores interesados en el proceso decisorio. Por último, y de manera muy importante, el cuerpo normativo marca lineamientos a los actores para el proceso decisorio. 


\section{Tabla 7: Desagregación de la Variables propias del Parámetro de Formalización del Proceso de Toma de Decisiones}

\begin{tabular}{l|l|l|l}
\hline Post-Burocracia & $\begin{array}{l}\text { Relativamente } \\
\text { orientada a la Post- } \\
\text { Burocracia }\end{array}$ & $\begin{array}{l}\text { Relativamente } \\
\text { Orientada a la APT }\end{array}$ & $\begin{array}{l}\text { Administración } \\
\text { Pública Tradicional }\end{array}$ \\
\hline Cuatro características & Tres características & Dos características & $\begin{array}{l}\text { Una, o ninguna, } \\
\text { característica }\end{array}$ \\
\hline
\end{tabular}

Fuente: Elaboración Propia.

\section{d) Dispersión de la atención en el proceso de toma de decisiones}

La atención de los individuos dentro de una organización, y de las organizaciones en sí es un bien escaso (Simon, 1997). La forma en que una organización considera uno o más temas en un único proceso decisorio, permite conocer con qué tanta capacidad para la resolución de los problemas se cuenta y el grado de satisfacción al que se dejarán de buscar más soluciones. Por ello, mientras que los problemas y las soluciones compiten entre sí por participantes y ventanas de oportunidad (Cohen, March, \& Olsen, 2011), será diferente la forma en que esto suceda en una organización orientada a la Post-Burocracia de una organización orientada a la Administración Pública Tradicional. Para el primer tipo de organización, la orientada hacia la post-burocracia, la dispersión de la atención será menor. Los temas a tratar estarán fuertemente vinculados con la reforma en curso, pero con ningún otro. En una organización orientada hacia la Administración Pública Tradicional, no. La atención será distribuida entre distintos temas ajenos a la decisión actual.

Para esto se consideran el número de temas que se tratan al momento de tomar una decisión. Mientras menos temas se traten, más se situaría la organización en el polo de post-burocracia. Operativamente se consideran de uno a dos temas por proceso decisional. El polo opuesto considera de cinco temas en adelante. El segundo de los componentes de la variable es la relación entre las decisiones. Se valora si éstas tienen impacto entre ellas. El siguiente componente de la variable considera la búsqueda y análisis de información sobre la decisión específica. El último de los componentes 
de la variable pregunta si se analiza información sobre todos y cada uno de los temas tratados. Si dichas prácticas se llevan a cabo regularmente, se considera a la organización como una que, en el componente, está en Post-Burocracia. Se utiliza el procedimiento de un promedio. Donde "regularmente" valdría cuatro puntos y "nunca", uno. Para el número de temas, el valor de cuatro corresponde a "De uno a dos temas" y para el valor uno, "De cinco temas en adelante".

\section{Tabla 8: Desagregación de la Variables propias del Parámetro de Dispersión de la Atención el Proceso de Toma de Decisiones}

\begin{tabular}{|c|c|c|c|c|}
\hline & Post-Burocracia & $\left|\begin{array}{l}\text { Relativamente } \\
\text { orientada a la } \\
\text { Post-Burocracia }\end{array}\right|$ & $\begin{array}{l}\text { Relativamente } \\
\text { Orientada a la } \\
\text { APT }\end{array}$ & $\begin{array}{l}\text { A d m in is tración } \\
\text { Pública Tradicional }\end{array}$ \\
\hline $\begin{array}{l}\text { Número de } \\
\text { Temas que tratan } \\
\text { en el momento } \\
\text { de la RA }\end{array}$ & De uno a dos & De dos a tres & De tres a cuatro & De cinco en adelante \\
\hline $\begin{array}{l}\text { Relacionan el } \\
\text { impacto de una } \\
\text { decisión con otras } \\
\end{array}$ & Regularmente & Algunas veces & Pocas veces & Raramente \\
\hline $\begin{array}{l}\text { Se busca y analiza } \\
\text { i n for m a c i ón } \\
\text { sobre el tema de } \\
\text { la RA }\end{array}$ & Regularmente & Algunas veces & Pocas veces & Raramente \\
\hline $\begin{array}{l}\text { Se busca y analiza } \\
\text { i n for m a c i ó n } \\
\text { sobre cada uno de } \\
\text { los temas tratados }\end{array}$ & Regularmente & Algunas veces & Pocas veces & Raramente \\
\hline
\end{tabular}

Fuente: Elaboración Propia.

\section{e) Causalidad de la decisión}

La última variable corresponde a lo que aquí se llama causalidad en la toma de decisión. Encontrando que la eficacia decisional es una relación de causalidad explícita y verificable entre la acción y las metas (Aguilar Villanueva L. F., 2010), se aprecia como distinta, aún a nivel discursivo, el tratamiento de causalidad entre las organizaciones situadas en una orientación distinta. 
En una organización orientada a la post-burocracia el proceso de toma de decisión define fuertemente la relación de las acciones, derivadas por la decisión, con las metas y objetivos. Mientras que dicha relación es débil en una organización orientada hacia la Administración Pública Tradicional, es fuerte cuando está orientada hacia la Post-Burocracia.

Tabla 9: Desagregación de la Variables propias del Parámetro de Causalidad de la Decisión

\begin{tabular}{l|l|l|l|l}
\hline & Post-Burocracia & $\begin{array}{l}\text { Relativamente } \\
\text { orientada a la } \\
\text { Post-Burocracia }\end{array}$ & $\begin{array}{l}\text { Relativamente } \\
\text { Orientada a la } \\
\text { APT }\end{array}$ & $\begin{array}{l}\text { Ad m in istración } \\
\text { Pública Tradicional }\end{array}$ \\
$\begin{array}{l}\text { Se busca que los } \\
\text { objetivos y las } \\
\text { acciones decididas } \\
\text { sean relacionadas } \\
\text { causalmente }\end{array}$ & Regularmente & Algunas veces & Pocas veces & Raramente \\
\hline
\end{tabular}

Fuente: Elaboración Propia.

Para clasificar cada uno de los elementos estructurales del proceso de toma de decisiones, los resultados de cada componente ubicarían a la organización dentro del siguiente continuo: 


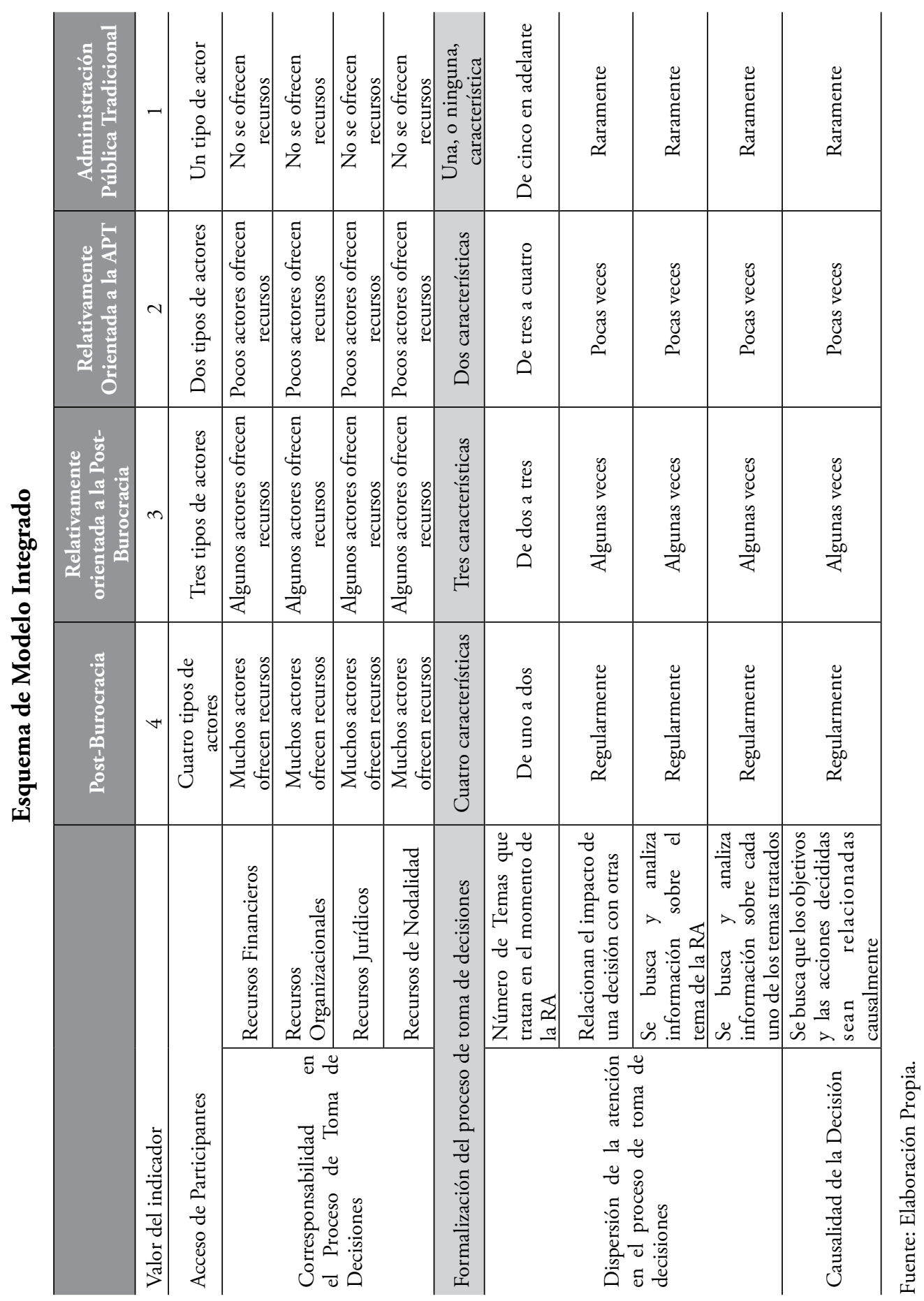


Esta matriz es la que permitiría ubicar la orientación en la que se sitúa la organización estudiada. Cada uno de los elementos puede vincularse hacia el éxito, o fracaso, de la reforma administrativa.

\subsection{VARIABLE INDEPENDIENTE: ÉXITO DE LA REFORMA AdMINISTRATIVA}

En un ejercicio reciente Klijn, Steijn y Edelenbos (2010) investigaron qué tipo de herramientas de gestión se vinculaban positivamente con el éxito en el manejo de proyectos ambientales. Para el ejercicio de estudio, los autores enumeraron una lista de prácticas de gestión que los funcionarios utilizaban en su trabajo. Sistematizaron las respuestas e hicieron el análisis estadístico necesario para encontrar aquellas prácticas que se consideraban, por parte de la comunidad de profesionales en manejo ambiental, como mejores para el éxito de los proyectos. En la investigación se adopta esta consideración metodológica. La percepción de éxito de la reforma administrativa, por parte del funcionariado, es de lo que se apropia y problematiza el estudio. Se profundiza sobre lo que se entiende como éxito de reforma administrativa. Después, presentaré la estrategia de investigación.

Se plantea la noción recuperando algunas propuestas pertenecientes a la literatura sobre implementación. Concretamente de Wildawsky y Pressman (1998) y Weimer y Vinning (2004). Del primero se rescata la idea de que la política pública, en este caso RA, es lo que realmente sucede. No es sólo lo que se dice que se hará, es lo que se hizo. De los otros dos autores, se hace valer la noción de implementación que ofrecen y que definen como "el acoplamiento" de decisiones entre actores. Dicho acoplamiento significa consenso al final de cuentas; consensos que son percepciones, percepciones que pueden ser agregadas. Las percepciones, junto con la realidad objetiva, intervienen en el constructo organizacional (Marsden, 1997) (Beltrán Villalva, 2003). Por ello, el éxito total de la reforma administrativa es cuando, después de iniciado el proceso de implementación, los actores involucrados concuerdan en el éxito de la misma. En el presente estudio, el hecho de que lo que se implementó y lo que se planificó no corresponda linealmente, no equivale a una reforma administrativa fallida. Es el consenso sobre el éxito de la misma lo que da la medida. En este sentido, la reforma administrativa se considera como institucional en un nivel medio, instrumental o capilar de la realidad gubernamental; considerando que las instituciones pueden 
entenderse en distintos niveles (Ostrom, 2000) (Jütting, 2003), aquí interesa la reforma administrativa que se da, de acuerdo a Ostrom (2000), en el nivel de análisis colectivo e individual.

Dada la definición de reforma administrativa, el consenso que haya sobre el logro de objetivos y metas planteadas, en relación con el cambio de tareas, es uno de los términos de mi medida de éxito. Cuando el momentum, o ventana de oportunidad, se ha aprovechado, de manera tal que se ha empujado la reforma administrativa, entonces podemos hablar de éxito (Kingdon, 1997).

\subsection{Metodología}

En este y siguientes párrafos, se presentan los puntos de orden metodológico. El uso de los instrumentos, hipótesis de trabajo, estrategias de investigación y construcción del caso.

Se optó por una estrategia de investigación mixta. Se realizaron entrevistas en profundidad a actores claves. De ellas se recuperan algunos puntos para caracterizar el proceso decisorio. Por otra parte, se aplicaron cuestionarios a todos los miembros de la organización. El cuestionario contaba con 31 reactivos. Estos reactivos alimentan a los indicadores de las seis variables manejadas. Los reactivos se construyeron en escala de Likert de cuatro puntas con miras a forzar una toma de posición por parte de los encuestados.

En términos de metodología para el estudio de casos, recurro fuertemente a Gunderman (2008) y Yin (2002). Este estudio de caso es uno de carácter instrumental, para el cual el fenómeno específico estudiado es una entidad digna de especial atención: la reforma administrativa. Se aspira a que el estudio sirva para explicar el proceso de toma de decisiones organizacionales de la reforma administrativa en gobiernos. El caso es una situación organizacional, la cual, a través del modelo, puedo conectar de tal manera que haya una salida teórica a la explicación del fenómeno estudiado.

Las restricciones utilizadas permiten, metodológicamente, ajustar el análisis fuera de su veta puramente histórica y abocarse a la percepción de los actores involucrados.

Para formalizar el proceso de investigación, se diseñó una pregunta de investigación operativa. Ésta reza como sigue: ¿Qué permite el éxito de la reforma administrativa 
como proceso de toma de decisiones? Para responder la pregunta, se utiliza la siguiente hipótesis de trabajo: Hay mayor éxito en la reforma administrativa, cuando la estructura de toma de decisiones en una organización está más orientada hacia la Postburocracia que cuando está más orientada a la Administración Pública Tradicional.

A través del análisis de los datos que ofrezcan los miembros de la organización, se espera verificar o refutar la hipótesis de investigación, y entonces, responder la pregunta de investigación.

Para el estudio de caso considero una hipótesis explicativa rival. Considerando que las relaciones de causalidad, fuerte, entre variables independiente y dependiente, es siempre objeto de discusión, disputa y refutación, se encuentra adecuado proponer una relación causal, una hipótesis rival. Para que, si fuese verificada, pudiera problematizar a la hipótesis de trabajo. Se propone que "Mientras más edad de los actores en la organización, mayor será la correlación positiva con el éxito de la reforma administrativa". La hipótesis previa atiende a la dimensión demográfica de la organización y se ha utilizado recientemente para tratar de explicar la reforma administrativa (Christensen \& Laegrid, 2009).

Incluye como supuestos teóricos que:

- Mientras más edad de los participantes, llevarán mayores recursos en términos de experiencia, capacidades, habilidades y conocimientos.

- Dichas experiencias, capacidades, habilidades y conocimientos permitirán un proceso de toma de decisión más eficaz.

Haciendo el análisis cuantitativo se podrá saber si hay, por lo menos, una correlación entre variables demográficas y éxito de la reforma administrativa. Haciendo que el peso de la estructura de toma de decisión sea menor o, de plano, nulo.

\section{Construcción del Estudio de Caso: La Organización "Dirección de Telecomunicaciones y Sistemas del Municipio de Zapopan, Jalisco”}

La Dirección de Telecomunicaciones y Sistemas del Municipio de Zapopan en el Estado de Jalisco, de acuerdo al Reglamento Interno del Ayuntamiento y la Administración Pública Municipal de Zapopan Jalisco, depende estructuralmente de la Oficialía Mayor Administrativa de la Municipalidad. En dicho Reglamento 
se dicta como una función de la Oficialía el "Establecer la normatividad aplicable en la administración pública municipal en materia de informática y proporcionar los servicios de asesoría técnica, asi como de instalación y mantenimiento del equipo de cómputo y telecomunicaciones" (Gobierno Municipal de Zapopan, 2011).

El Reglamento en Materia de Informática y Cómputo para el Municipio de Zapopan (Gobierno Municipal de Zapopan, 2005) delimita la función como "proporcionar apoyo tecnológico a las tareas administrativas, operativas, de planeación, de capacitación y gestión, de la administración municipal'. Esta competencia específica circunscribe el ámbito de competencia de la Dirección de Telecomunicaciones y Sistemas (en adelante, Dirección). De acuerdo a Mintzberg (2005) se consideraría, en un esquema organizacional que abarcara a todo el gobierno municipal, que la Dirección es una forma organizacional de tecno-estructura; incide lateralmente en el trabajo de línea, homologándolo y coordinando políticas internas en un ámbito organizacional específico.

La organización cuenta con un total de 68 miembros. Formalmente se divide en seis departamentos: De atención a usuarios, De redes e internet, De telefonía, De desarrollo, De radiocomunicaciones y De proyectos. Cuenta, además, con dos áreas de apoyo: la del Coordinador y la Secretaría de la Dirección, así como la Dirección (Gobierno Municipal de Zapopan, 2011).

El programa "Zapopan Ciudad Digital" fue una iniciativa originada por el Presidente Municipal Héctor Vielma, para el periodo 2010-2012. Durante el periodo de transición de gobierno, el Presidente Municipal se acercó a la maestra Yolanda Martínez Mancilla y al ingeniero Rodrigo Herrera (entrevista a Asesor de Informática, 2011) para que diseñaran una política integral de tecnologías de información y comunicaciones. El programa comenzó a trabajarse durante el primer trimestre del 2010 (entrevista a Asesor de Informática, 2011).

En palabras de la Directora, Yolanda Martínez Mancilla, Zapopan Ciudad Digital, tiene como objetivo:

“(...) Utilizar la tecnología de la información como un eje de politica pública, que nos permita mejorar nuestra relación de gobierno con los ciudadanos, que nos permita ser más eficientes, que nos permita reducir gastos operativos y dedicar más gastos a inversión, que nos permita transformar totalmente la manera en cómo el 
gobierno se dimensiona a si mismo y ofrece servicios." (entrevista a Directora de Telecomunicaciones y Sistemas del Municipio de Zapopan, 2011).

El programa tiene un modelo de gestión en tres grandes rubros: e-infraestructura, e-gestión y e-comunidad (entrevista a Asesor de Informática, 2011). El primer rubro considera la mejora y puesta al día de equipos. El rubro de e-gestión busca la homologación interna de toda información, datos y programas. El último rubro "(...) es acercar la tecnología a la ciudadanía, es mejorar la forma de atención a la ciudadanía a través de la tecnología, es toda la parte de e-seguridad, fortalecer la parte de infraestructura o de software dirigidos a la seguridad del ciudadano y todo el manejo de redes" (entrevista a Asesor de Informática, 2011).

Como política, el diseño de Zapopan Ciudad Digital fue relativamente sencillo. La programación informática de la plataforma digital se elaboró en poco tiempo y el estudio costo beneficio arrojaba economías considerables (Gobierno Municipal de Zapopan, 2010). Según señalan los entrevistados, la problemática del éxito del proceso decisorio ocurrió durante su implementación.

Antes de la reforma administrativa contenida en Zapopan Ciudad Digital, se tenían alrededor de 516 trámites y servicios. Ninguno de estos se podía prestar de manera electrónica. Lo más avanzado era la consulta vía página web. No había, por ejemplo, pago en línea ni manejo electrónico de documentos. Había sistemas de gestión de calidad, pero con carencias en cuanto a inter-operatividad (Gobierno Municipal de Zapopan, 2010).

Después de la reforma administrativa se pueden realizar pagos a través de internet, se está en proceso de convergencia en sistemas de gestión en red. (entrevista a Directora de Telecomunicaciones y Sistemas del Municipio de Zapopan, 2011) (entrevista a Asesor de Informática, 2011).

Se aplicó un cuestionario a todos los miembros de la organización. Hubo dos cuestionarios inválidos. Para el modelo integrado se realizaron los promedios de los sub-indicadores correspondientes a las variables Dispersión General de la Atención y Corresponsabilidad en el Proceso Decisorio. Se redondearon los promedios a efectos de obtener valores cerrados. 


\section{ANÁlisis DE RESUltados}

Se realizó la sistematización de los cuestionarios y se trató de aplicar un modelo de análisis multivariante sencillo, sin embargo, dada la distribución de respuestas resultó más conveniente un manejo más bien descriptivo de los resultados (Martínez Arias, 1999). Se hizo una correlación de variables para conocer aquellas que más fuertemente están vinculadas entre sí.

Se presentan los resultados de los cuestionarios y se interpretan en función del marco de análisis construido. En algunos casos se sugiere, de manera tentativa, una respuesta a las preguntas de investigación.

La distribución de frecuencias de cada una de las variables es la siguiente:

Considerando que la estructura de acceso al proceso de toma de decisión permitía, de acuerdo a los miembros de la organización, por lo menos tres tipos de actores (Internos, externos y nivel gerencial/operativo), es de una estructura relativamente orientada a la gobernanza en el marco de análisis elaborado aquí.

\section{Ilustración 2: Estructura de acceso al Proceso de Toma de Decisición}

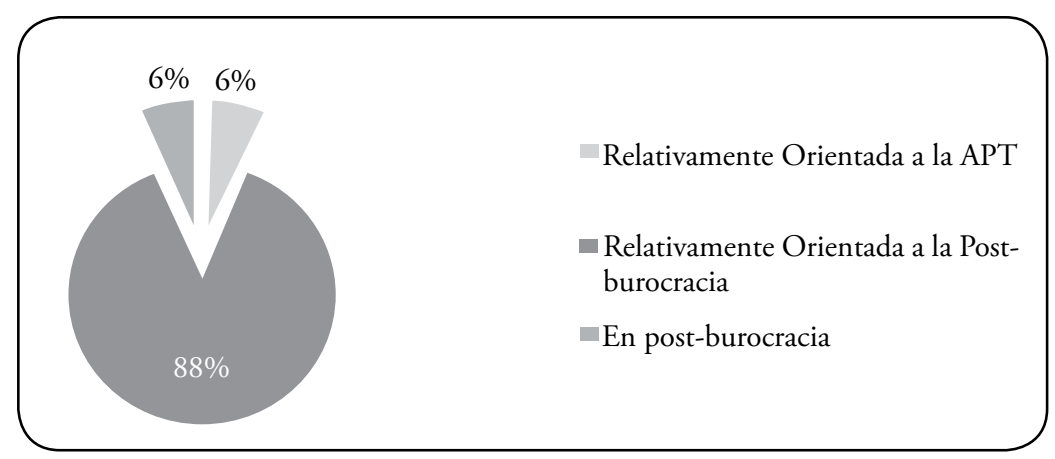

Fuente: Elaboración Propia.

Se subraya que la orientación de la estructura de acceso de participantes sugiere un alto flujo de actores organizacionales. Si se caracteriza el proceso decisorio de la organización para la reforma administrativa específica, se debiera caracterizar como uno donde entraron y salieron muchos y distintos actores a lo largo del proceso. 
El 80,3\% de los resultados muestra que la corresponsabilidad en el proceso de toma de decisiones no está en la orientación de la Post-burocracia. Un poco menos de la mitad de los encuestados señaló que, en promedio, los actores que participaron en el proceso de toma de decisiones no llevaban recursos financieros, organizativos, legales y nodales. Además, que cuando los llevaban eran de poca cuantía.

\section{Ilustración 3: Corresponsabilidad en el Proceso de Toma de Decisiones}

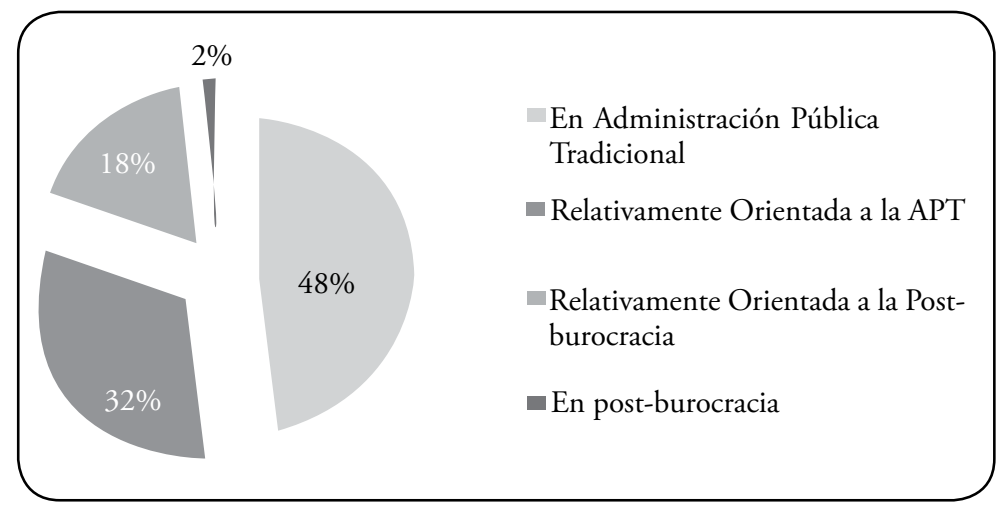

Fuente: Elaboración Propia.

Caracterizando el proceso de toma de decisiones para la reforma administrativa concreta, se observaría que actores externos e internos, gerenciales y de base entraban y salían durante el proceso de manera fluida, pero pocos llevaban recursos para la toma de decisiones. Los actores con recursos, ofrecían pocos.

De acuerdo a los resultados de la encuesta, la variable de formalización del proceso de toma de decisiones presenta más rasgos de la orientación hacia la Postburocracia, en un sentido pleno y relativo, que rasgos de la orientación contraria. Esto nos lleva a pensar que la formalización vivida por los participantes durante el proceso decisional era alta. 


\section{Ilustración 4: Formalización de Toma de Dicisiones}

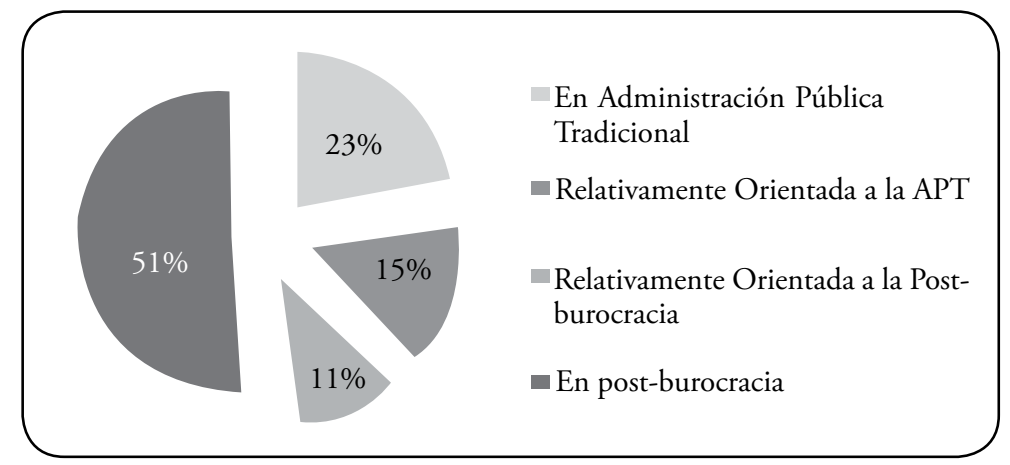

Fuente: Elaboración Propia.

Aunado con los rasgos estructurales previamente caracterizados, esto lleva a considerar que algunas reglas formalmente establecidas, esto es escritas, circunscribían el comportamiento de los actores durante el proceso decisorio. Ya sea en cuanto a quiénes podían participar, qué podrían decidir, bajo qué condiciones y cómo podrían haberlo hecho.

Un punto muy interesante de los resultados del estudio es que la dispersión general de la atención se orienta hacia la gobernanza. De acuerdo al tratamiento dado a la variable, esto significa que, regularmente, se trataban pocos temas, se buscaba información de manera extensiva sobre los temas en juego, se vinculaban impactos de la decisión con la reforma administrativa buscada y se relacionaba el proceso decisorio específico, el de la reforma administrativa, con otros procesos decisorios.

\section{Ilustración 5: Dispersión de la atención en el proceso de toma de decisiones}

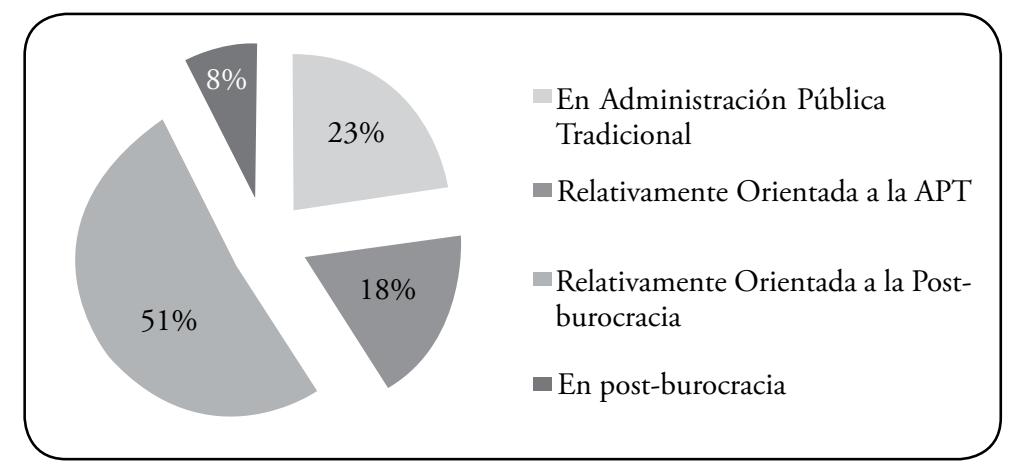

Fuente: Elaboración Propia. 
Esto significaría que el proceso de toma de decisiones logró que, con muchos actores, pocos recursos y un alto grado de formalización, se mantuviera centrado en la reforma administrativa.

La última variable del estudio permitía conocer qué tanto se atribuía una relación de causalidad entre el objetivo de la reforma y la toma de decisiones. El ochenta por ciento de los encuestados estableció una relación de causalidad que podemos considerar alta o muy alta entre lo que se planteaba como objetivo la reforma administrativa y lo que se decidía.

\section{Ilustración 6: Causalidad de la Decisión}

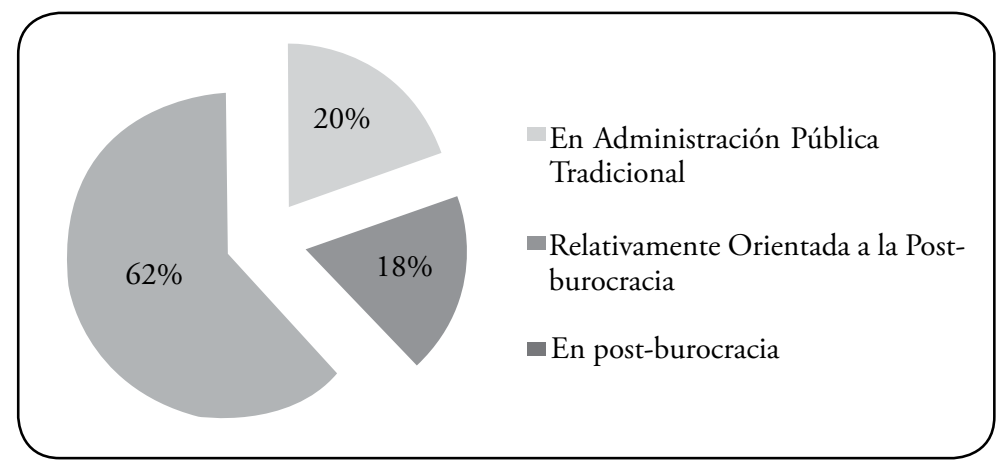

Fuente: Elaboración Propia.

De acuerdo a la mayoría de los encuestados las acciones y los objetivos eran congruentes entre sí. Además de que se buscaba que la congruencia instrumental apareciera regularmente durante el proceso decisional.

La interpretación general de los resultados de cada variable llevaría a caracterizar a la estructura de toma de decisiones de la Dirección de Telecomunicaciones y Sistemas de Zapopan como una que está relativamente orientada a la Administración Pública Tradicional. Tres de cinco variables se ubican en dicho espacio del continuo Post-burocracia-Administración Pública Tradicional.

Esto, sin embargo, no muestra nada más que una descripción organizacional. La vinculación de la descripción, como un conjunto de variables explicativas, debe hacerse a la variable dependiente. En este caso, el éxito de la reforma 
administrativa. A continuación se muestra el resultado de la percepción de éxito de la reforma administrativa entre los miembros de la organización.

La mayoría de los integrantes de la organización consideran como exitosa la reforma administrativa. Debiéndose considerar factores como el tiempo, ya que el programa lleva a la fecha en que esto se escribe dos años de trabajarse, o el hecho de que el Presidente Municipal sea el principal patrocinador político (entrevista a Asesor de Informática, 2011), El programa "Zapopan Ciudad Digital" no contaba con indicadores de éxito o desempeño 'duros'. Parámetros como número de entradas a la página electrónica, ahorros por periodo, aumento en consultas telefónica, etcétera, no se usaron como medidas de éxito de la reforma administrativa, sino que se consideraba el grado de aceptación en la administración municipal como medida de éxito (entrevista a Directora de Telecomunicaciones y Sistemas del Municipio de Zapopan, 2011).

Los resultados de la encuesta son consistentes con el criterio que manifestaron los entrevistados. Por el mismo patrón de resultados, la estrategia metodológica original de utilizar un modelo multivariante logit no es factible. Encontrar, entonces, un parámetro de probabilidad como medida proxy de causalidad no es posible para el ejercicio. No puedo asegurar una relación probabilística entre las variables independientes y la dependiente.

Ante esto es difícil validar, o no, la hipótesis central de la investigación. No es posible considerar si una estructura de toma de decisiones orientada a la gobernanza es mejor para la reforma administrativa que una estructura orientada a la Administración Pública Tradicional.

Dado que más variables tendieron, en promedio, a acercarse al polo de Administración Pública Tradicional, podríamos rechazar la hipótesis central y la hipótesis derivada. Sin embargo, insisto, no es posible hacer una comprobación lineal o probabilística de esto.

Con el fin de un mejor análisis se realizó una correlación bi-variada entre las variables. Si bien no se puede encontrar una relación como la dicha en el párrafo anterior, se podrá interpretar el comportamiento de los factores estructurales al proceso de toma de decisión. 
Tabla 18: Tabla De Correlaciones Entre Variables

\begin{tabular}{|c|c|c|c|}
\hline \multicolumn{4}{|c|}{ Correlaciones entre variables } \\
\hline & & $\begin{array}{l}\text { Éxito de la Reforma } \\
\text { Administrativa }\end{array}$ & $\begin{array}{l}\text { Estructura de Acceso de } \\
\text { Participantes en el Proceso de } \\
\text { Toma de Decisiones }\end{array}$ \\
\hline \multirow{3}{*}{$\begin{array}{l}\text { Éxito de la Reforma } \\
\text { Administrativa }\end{array}$} & $\begin{array}{l}\text { Correlación de } \\
\text { Pearson }\end{array}$ & 1 & -0.151 \\
\hline & Sig. (2 Colas) & & 0.225 \\
\hline & $\mathrm{N}$ & 66 & 66 \\
\hline \multirow{3}{*}{$\begin{array}{l}\text { Estructura de Acceso } \\
\text { de Participantes en el } \\
\text { Proceso de Toma de } \\
\text { Decisiones }\end{array}$} & $\begin{array}{l}\text { Correlación de } \\
\text { Pearson }\end{array}$ & -0.151 & 1 \\
\hline & Sig. (2 Colas) & 0.225 & \\
\hline & $\mathrm{N}$ & 66 & 66 \\
\hline \multirow{3}{*}{$\begin{array}{l}\text { Corresponsabilidad } \\
\text { en el proceso de toma } \\
\text { de decisiones }\end{array}$} & $\begin{array}{l}\text { Correlación de } \\
\text { Pearson }\end{array}$ & 0.084 & 0.178 \\
\hline & Sig. (2 Colas) & 0.502 & 0.153 \\
\hline & $\mathrm{N}$ & 66 & 66 \\
\hline \multirow{3}{*}{$\begin{array}{l}\text { Formalización del } \\
\text { Proceso de Toma de } \\
\text { Decisiones }\end{array}$} & $\begin{array}{l}\text { Correlación de } \\
\text { Pearson }\end{array}$ & 0.183 & 0.092 \\
\hline & Sig. (2 Colas) & 0.141 & 0.461 \\
\hline & $\mathrm{N}$ & 66 & 66 \\
\hline \multirow{3}{*}{$\begin{array}{l}\text { Dispersión de la } \\
\text { atención en el proceso } \\
\text { de toma de decisiones }\end{array}$} & $\begin{array}{l}\text { Correlación de } \\
\text { Pearson }\end{array}$ & 0.083 & -0.239 \\
\hline & Sig. (2 Colas) & 0.506 & 0.053 \\
\hline & $\mathrm{N}$ & 66 & 66 \\
\hline \multirow{3}{*}{$\begin{array}{l}\text { Causalidad de la } \\
\text { Decisión }\end{array}$} & $\begin{array}{l}\text { Correlación de } \\
\text { Pearson }\end{array}$ & 0.108 & -0.113 \\
\hline & Sig. (2 Colas) & 0.386 & 0.368 \\
\hline & $\mathrm{N}$ & 66 & 66 \\
\hline
\end{tabular}

**. La correlación es significativa en el nivel 0.01

Fuente: Elaboración Propia. 


\begin{tabular}{|c|c|c|c|}
\hline $\begin{array}{l}\text { Corresponsabilidad en el } \\
\text { proceso de toma de decisiones }\end{array}$ & $\begin{array}{l}\text { Formalización del Proceso de } \\
\text { Toma de Decisiones }\end{array}$ & $\begin{array}{l}\text { Dispersión de la } \\
\text { atención en el } \\
\text { proceso de toma } \\
\text { de decisiones }\end{array}$ & $\begin{array}{l}\text { Causalidad de la } \\
\text { Decisión }\end{array}$ \\
\hline 0.084 & 0.183 & 0.083 & 0.108 \\
\hline 0.502 & 0.141 & 0.506 & 0.386 \\
\hline 66 & 66 & 66 & 66 \\
\hline 0.178 & 0.092 & -0.239 & -0.113 \\
\hline 0.153 & 0.461 & 0.053 & 0.368 \\
\hline 66 & 66 & 66 & 66 \\
\hline \multirow[t]{2}{*}{1} & $.330^{* *}$ & 0.218 & $.339^{* *}$ \\
\hline & 0.007 & 0.079 & 0.005 \\
\hline 66 & 66 & 66 & 66 \\
\hline $.330^{* *}$ & 1 & $.435^{* *}$ & $.342^{* *}$ \\
\hline 0.007 & & 0 & 0.005 \\
\hline 66 & 66 & 66 & 66 \\
\hline 0.218 & $.435^{* *}$ & 1 & $.663^{* *}$ \\
\hline 0.079 & 0 & & 0 \\
\hline 66 & 66 & 66 & 66 \\
\hline $.339^{* *}$ & $.342^{* *}$ & $.663^{* *}$ & 1 \\
\hline 0.005 & 0.005 & 0 & \\
\hline 66 & 66 & 66 & 66 \\
\hline
\end{tabular}


La "Formalización del Proceso de Toma de Decisiones" tuvo una correlación significativa y positiva, pero relativamente baja, con la "Corresponsabilidad en el proceso de toma de decisiones", la "Dispersión de la atención en el proceso de toma de decisiones" y la "Causalidad de la Decisión".

También hubo una correlación significativa entre la variable de "Corresponsabilidad en el proceso de toma de decisiones" con la "Causalidad de la Decisión". Por último, la correlación más importante entre variables fue la que tuvieron las variables de "Dispersión de la atención en el proceso de toma de decisiones" con la "Causalidad de la Decisión". Todas las correlaciones fueron positivas.

\section{Tabla 19: Coeficientes de correlaciones estadísticamente significativas entre variables}

\begin{tabular}{|c|l|l|c|}
\hline Orden & \multicolumn{2}{|l|}{ Variables Correlacionadas } & Coeficientes \\
\hline 1 & $\begin{array}{l}\text { Dispersión de la atención en el } \\
\text { proceso de toma de decisiones }\end{array}$ & Causalidad de la Decisión & 0.663 \\
\hline 2 & $\begin{array}{l}\text { Formalización del Proceso de Toma } \\
\text { de Decisiones }\end{array}$ & $\begin{array}{l}\text { Corresponsabilidad en el proceso } \\
\text { de toma de decisiones }\end{array}$ & 0.435 \\
\hline 3 & $\begin{array}{l}\text { Formalización del Proceso de Toma } \\
\text { de Decisiones }\end{array}$ & $\begin{array}{l}\text { Dispersión de la atención en el } \\
\text { proceso de toma de decisiones }\end{array}$ & 0.342 \\
\hline 4 & $\begin{array}{l}\text { Formalización del Proceso de Toma } \\
\text { de Decisiones }\end{array}$ & Causalidad de la Decisión & 0.339 \\
\hline 5 & $\begin{array}{l}\text { Corresponsabilidad en el proceso de } \\
\text { toma de decisiones }\end{array}$ & Causalidad de la Decisión & 0.33 \\
\hline
\end{tabular}

Fuente: elaboración propia.

Pareciera que mientras más cambia la orientación de la organización en dichas variables, hacia la orientación de la Post-Burocracia, éstas cambian positivamente entre sí. Mientras haya más causalidad en un proceso decisional, menos disperso sería. Amén de que mientas más corresponsabilidad haya, mayor sería la causalidad de la decisión.

Es necesario apuntar que las variables "Estructura de Acceso de Participantes en el Proceso de Toma de Decisiones" y el "Éxito de la Reforma Administrativa" fueron variables sin alguna correlación significativa entre ellas o con ninguna otra variable.

Considerando que el estudio de caso requería suplir requisitos de validación, se consideró buscar una explicación alternativa. Dicha explicación consistía 
en establecer si hay una correlación significativa entre el éxito de la reforma administrativa, mi variable dependiente, y la edad de los participantes. No se encontró una correlación significativa. No se optó por alguna técnica distinta pues el modelo básico, dada la distribución de respuestas de los encuestados, no permitía más que el reporte y la correlación entre variables. Por lo tanto, la opción buscó satisfacer criterios de consistencia entre las técnicas aplicadas para cada una de las hipótesis. La Tabla 20 muestra que no hubo una correlación significativa entre las variables. Lo que lleva a considerar que la experiencia, o la dimensión demográfica de la organización, no fueron relevantes para el proceso de toma de decisiones en la reforma administrativa.

Tabla 20: Correlación Entre Variables de Hipótesis Alternativa

\begin{tabular}{|c|c|c|c|}
\hline \multicolumn{4}{|c|}{$\begin{array}{r}\text { Correlación entre Edad de los Miembros de la } 0 \\
\text { Administrativa }\end{array}$} \\
\hline & & $\begin{array}{l}\text { Edad de los Miembros } \\
\text { de la Organización }\end{array}$ & $\begin{array}{l}\text { Éxito de la Reforma } \\
\text { Administrativa }\end{array}$ \\
\hline \multirow{3}{*}{$\begin{array}{l}\text { Edad de los Miembros de } \\
\text { la Organización }\end{array}$} & $\begin{array}{l}\text { Correlación de } \\
\text { Pearson }\end{array}$ & 1 & 0.057 \\
\hline & Sig. (2-colas) & & 0.655 \\
\hline & $\mathrm{N}$ & 67 & 65 \\
\hline \multirow{3}{*}{$\begin{array}{l}\text { Éxito de la Reforma } \\
\text { Administrativa }\end{array}$} & $\begin{array}{l}\text { Correlación de } \\
\text { Pearson }\end{array}$ & 0.057 & 1 \\
\hline & Sig. (2-colas) & 0.655 & \\
\hline & $\mathrm{N}$ & 65 & 66 \\
\hline
\end{tabular}

Fuente: elaboración propia.

\section{Conclusiones}

El proceso de toma de decisiones organizacionales es un proceso complejo. Dificultoso de aprehender y desafiante como objeto de estudio. Esto se muestra a lo largo del texto. Desde el nivel conceptual al metodológico hay una pléyade 
de consideraciones. En el trabajo aquí hecho se decidió por una estrategia de investigación inspirada en el modelo de bote de basura, donde se deseaba encontrar una relación entre el éxito de la reforma administrativa y el proceso de toma de decisiones, ya teniendo una orientación burocrática o una post-burocrática. A partir de una caracterización puntual es posible alentar una respuesta a las preguntas hechas.

De tal forma, la estructura de acceso de participantes es muy abierta. Los actores entran y salen, de manera fluida y con pocas restricciones. Mientras que la corresponsabilidad de los actores, al medrar en la organización durante el proceso de toma de decisiones, los participantes llevan pocos recursos y de estos pocos recursos que llevan, poco ofrecen. En términos del bote de basura "clásico" de Cohen, March y Olsen, hay poca energía en el proceso decisorio. En cuanto a la formalización, y curiosamente, durante el proceso de toma de decisiones tendiente a la reforma administrativa, en esta organización la formalización jugó un papel importante. Más rasgos de la orientación a la Post-Burocracia fueron los que observaban los actores organizacionales.

La dispersión de la atención era relativamente alta. Más bien orientado al polo de la administración pública tradicional. Es decir, la organización observaba distintos temas al mismo tiempo y los estudiaba, sin necesariamente disponer de estos de una manera ordenada.

La última variable, la causalidad decisional, lleva a considerar que el proceso de toma de decisiones no era lo más integral posible. Es decir, se estudiaban los temas, sí. Pero no de manera tal que abarcara toda la información posible y relevante al tema en cuestión.

Entonces, ¿cómo se elaboró la decisión? El proceso de toma de decisiones tendientes a la reforma administrativa, en pocas palabras, fue uno relativamente orientado a la Administración Pública Tradicional. Se puede considerar exitoso dado que la mayoría de los miembros de la organización lo consideraron así. Por su parte, resultó irrelevante la hipótesis demográfica para el éxito de la reforma administrativa. La correlación entre ambas variables no fue significativa. Un dato interesante es que tampoco hubo correlación entre alguna variable del modelo original y el éxito de la reforma administrativa. 
Con esto se puede caracterizar al proceso de toma de decisiones para la reforma administrativa, en la Dirección de Telecomunicaciones y Sistemas del Municipio de Zapopan, como uno con una amplia rotación de actores, donde los actores ofrecen pocos recursos de manera creíble durante la toma de decisiones. La toma de decisiones estaba encauzada en medios formales de toma de decisión; pero al fluir a través del proceso de toma de decisiones, el número de actores que entraban y salían no prestaban mucha atención a pocos temas; la dirigían a temas variados y dispersos. Por último, consideraban relaciones de causalidad, es decir de eficacia, de una manera clara, pero tímida: sin ir más allá de lo estrictamente importante.

Esta caracterización no puede tener un correlato con el éxito de la reforma administrativa. Sin embargo, la mayoría de los actores consideró como exitosa la reforma. En última instancia, algunos de los parámetros de la toma de decisiones fueron importantes entre sí. Se fortalecían unos con otros. El esquema de correlaciones entre los parámetros de la estructura de toma de decisiones, se puede representar gráficamente como sigue:

\section{Ilustración 8: Esquema de Correlaciones Entre Parámetros}

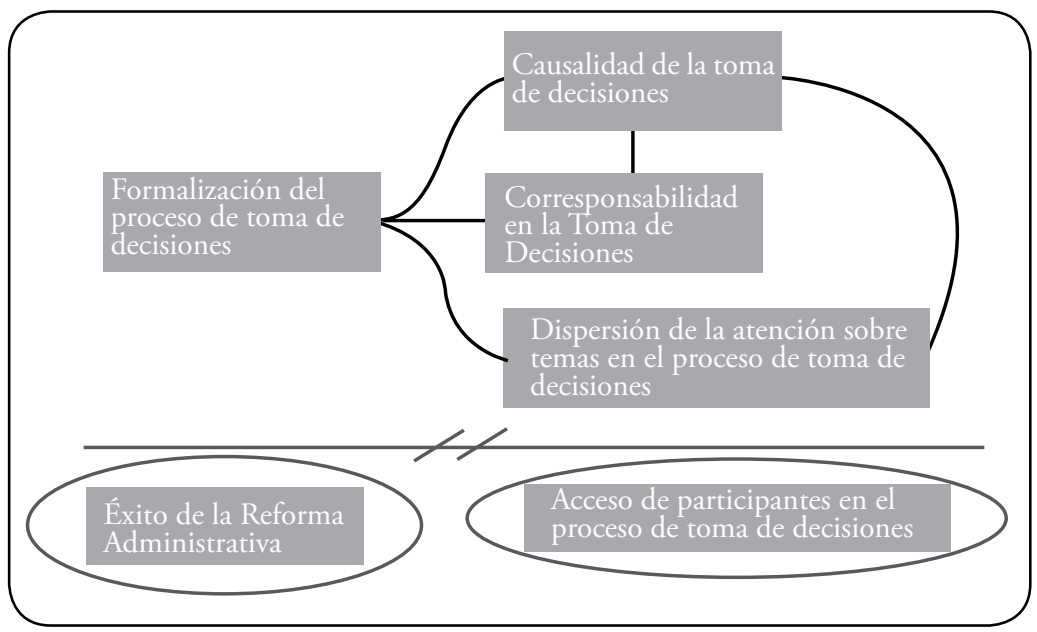

Elaboración Propia.

La dinámica de toma de decisiones lleva a una paradoja. ¿̨or quéhubo una percepción de éxito de la reforma administrativa cuando las variables no se correlacionaron ni pudieron establecerse en términos de causalidad? Si bien el modelo no llevó a 
una explicación fuerte, la hipótesis alternativa lo fue menos. No se encontró una correlación entre experiencia, entendida como edad, y éxito de la reforma.

La implicación en cuanto a la discusión de si la organización como Administración Pública Tradicional es más poderosa que la organización post-burocrática queda en el aire, pero con miras que piden una revalorización de cuestiones más clásicas en la administración pública, gobierno y Estado. Con un ligero sesgo hacia la Administración Pública Tradicional, en un caso de éxito de reforma, se antoja interesante saber si la eficacia gubernamental se mantiene con burocracias tradicionales en ambientes de cambio, complejización y diferenciación societal.

\section{REFERENCIAS}

Aguilar Villanueva, L. F. (2010). Gobernanza: El nuevo proceso de gobernar. México: Fundación Friedrich Naumann para la Libertad.

Aguilar Villanueva, L. F. (2011). Gobernanza pública para obtener resultados: marco conceptual y operacional. Programa de Naciones Unidas para el Desarrollo, Comité de Expertos en Administración Pública. Nueva York: Organización de las Naciones Unidas.

Aguilar Villanueva, L. F. (2011a). Políticas públicas y tranversalidad. En J. M. Ramos, J. Sosa, \& F. Acosta, La evalación de las políticas públicas en México (págs. 23-44). Tijuana: El Colegio de la Frontera Norte.

Allison, G. \& Zelikow, P. (1999). Essence of decision. Explaining the cuban missile crisis. (Segunda edición ed.). EEUU: Longman.

Ayala Espino, J. (2000). Mercado, elección pública e instituciones: Una revisión de las teorías modernas del Estado. (Segunda ed.). México DF: Universidad Nacional Autónoma de México, Miguel Ángel Porrúa.

Barzelay, M. (2003). La nueva gestión pública. Un acercamiento a la investigación y al debate de las políticas. México DF: Fondo de Cultura Económica.

Beltrán, M. (2003). La realidad social (Segunda ed.). Madrid: Tecnos.

Bolin, M. \& Härenstam, A. (2008). An Empirical Study of Bureaucratic and Post-Bureaucratic Characteristics in 90 Workplaces. Economic and Industrial Democracy, 29(4), 541-564.

Brunsson, N. (2009). Reform as routine: organizational change and stability in the modern world. NY: OxfordUniversityPress 
Brunsson, N. \& Olsen, J. (2007). La reforma de las organizaciones. México DF: CIDE.

Cabrero, E. (1997). Del administrador al gerente público (Segunda Edición). México DF: Instituto Nacional de Administración Pública.

Castells, M. (1996). Information Age (Vols. I, II, III). Blackwell.

Christensen, T. \& Laegrid, P. (2009). Coordination and Hybrid Governance; Theoretical and Empirical Challenges. Universidad de Bergen. Bergen: Stein Rokkan Centre for Social Studies.

Christensen, T. \& Laegrid, P. (2012). Governance and Administrative Reforms. LatinamericanEuropean Meeting in Organizational Studies (págs. 1-19). Axixic: European Group in Organizational Studies.

Christensen, T.; Lægreid, P.; Roness, P. \& Arne Røvik, K. (2007). Organisational Theory for the Public Sector: Instrument, Culture, Myth. New York: Routledge.

Cohen, M.; March, J. \& Olsen, J. (2011). El bote de basura como modelo de elección organizacional. Gestión y Politica Pública, 20(2), 247-290.

Crozier, M. (1974). El fenómeno burocrático (Segunda ed.). Buenos Aires, Argentina: Amorrurtu.

Crozier, M. \& Friedberg, E. (1990). El actor y el sistema. México Distrito Federal: Alianza Editorial.

Culebro, J. (2003). Cambio estructural. En D. Arellano, E. Cabrero \& A. del Castillo, Reformando al gobierno: una visión organizacional del cambio gubernamental. (pp. 171-220). México, Distrito Federal: Miguel Ángel Porrúa; Centro de Investigación y Docencia Económica.

Cyert, R. \& March, J. (1965). Teoría de las decisiones económicas de la empresa. México DF: Herrero.

DiMaggio, P. \& Powell, W. (1991). El nuevo institucionalismo en el análisis organizacional. México DF: Fondo de Cultura Económica.

Dussauge, M. (2009). La literatura comparada sobre reformas administrativas. Desarrollos, limitaciones y posibilidades. Gestión y política pública, XVIII(2), 439- 495.

Elster, J. (1991). Juicios salomónicos; Las limitaciones de la racionalidad como principio de decisión. Barcelona: Gedisa.

Elster, J. (2007). Explaining Social Behavior. More Nuts and Bolts for the Social Sciences. New York: Cambridge University Press. Second Edition.

Fayol, H. (1961). Administración industrial y general. Buenos Aires: El Ateneo.

Ferlie, E.; Lynn, L. \& Pollitt, C. (2007). Afterword. En E. Ferlie, L. Lynn \& C. Pollitt, The Oxford Handbookd of Public Management (págs. 720-730). New York: Oxford University Press. 
LA TOMA DE DECISIONES ORGANIZACIONALES EN UN PROCESO DE REFORMA ADMINISTRATIVA. EL GOBIERNO DIGITAL EN UN MUNICIPIO DE JALISCO, MÉXICO

Garvía, R. (1993). El problema de objetivos en organizaciones formales. Seminario del Centro de Estudios Avanzados en Ciencias Sociales (págs. 1-73). Madrid: Instituto Juan March.

Grey, C. \& Garsten, C. (2001). Trust, Control and Post-Bureaucracy. Organization Studies, 22(2), 229-250.

Gundermann, H. (2008). El método de los estudios de caso. En M. L. Tarres (Ed.), Observar, escuchar y comprender: Sobre la tradición cualitativa en la investigación social. (págs. 249288). México DF: Miguel Ángel Porrúa, FLACSO México, El Colegio de México.

Hall, R. (1962). Intraorganizational Structural Variations: Application of the Bureaucratic Model. Administrative Science Quarterly, 7(3), 295-308.

Heady, F. (2000). Administración pública: una perspectiva comparada. México, Distrito Federal: Fondo de Cultura Económica; Colegio Nacional de Ciencias Políticas y Administración Pública.

Hood, C. \& Margetts, H. (2007). The Tools of Goverment in the Digital Age. New York: Palgrave MacMillan.

Johnson, P.; Wood, G.; Brewster, C. \& Brookes, M. (2009). The Rise of Post-Bureaucracy: Theorists Fancy or Organizational Praxis? International Sociology, 24(1), 37-61.

Jütting, J. (julio de 2003). Institutions and Development: A Critical Review. Recuperado el 15 de 06 de 2012, de OECD Library: http://www.oecd-ilibrary.org/docserver/download/ fulltext $/ 5$ lgsjhvj780v.pdf?expires $=1341259163 \& i d=i d \&$ accname=guest $\&$ checksum $=8 D C$ AE6CB47375877BCB8204CC4FDF6C0

Kingdon, J. (1997). Agendas, Alternatives, and Public Policies. Segunda Edición. Longman.

Klijn, E.; Steijn, B. \& Edelenbos, J. (2010). The Impact of Network Management on Outcomes in Governance Networks. Public Administration, 88(4), 1063-1082.

Laufer, R. \& Burlaud, A. (1988). Dirección pública: gestión y legitimidad. Madrid: Instituto Naconal de Administración Pública.

Luhmann, N. (1997). Organización y decisión. Barcelona: Anthropos, Universidad Iberoamericana, Pontificia Universidad Católica de Chile.

Lynn, L. (2001). The Myth of the Bureaucratic Paradigm: What Traditional Public Administration Really Stood For. Public Administration Review, 61(2), 144-160.

Marsden, R. (1997). La política del análisis organizacional. Gestión y Política Pública, VI(2), 285-325.

Martínez, R. (1999). El análisis multivariante en la investigación científica. Madrid: La Muralla.

Merton, R. (1964). Teoría y estructura sociales (Primera edición en español ed.). Distrito Federal: Fondo de Cultura Económica. 
Mintzberg, H. (2005). La estructuración de las organizaciones. España: Ariel.

Olsen, J. (2001). Garbage Cans, New Institutionalism and the Study of Politics. American Political Science Review, 95(1), 191.

Osborne, D. \& Gaebler, T. (1992). Reinventing government: How the entrepreneurial spirit is transforming the public sector. Reading: Addison-Wesley Pub.

Ostrom, E. (2000). El gobierno de los bienes comunes. La evolución de las instituciones de acción colectiva. México DF: UNAM, CRIM, Fondo de Cultura Económica.

Parsons, W. (2007). Políticas Públicas: una introducción a la teoría y a la práctica del análisis de politicas públicas. México DF: Facultad Latinoamericana de Ciencias Sociales Sede México.

Pfeffer, J. (1981). Power in Organizations. Boston: Pitman.

Pollitt, C. \& Bouckaert. (2011). Public Management Reform: A Comparative Analysis of Public Management, Governance and the Neo-Weberian State (Tercera Edición ed.). Nueva York: Oxford University Press.

Resnik, M. D. (1998). Elecciones. Una introducción a la teoría de la decisión. Barcelona: Gedisa.

Simon, H. A. (1997). Administrative Behavior. A Study of Decision-Making Processes in Administrative Organizations. (Cuarta ed.). New York: Frees Press. Edición en español: Simon, Herbert A. (1962). El comportamiento administrativo: estudio de los procesos decisorios en la organización administrativa. Madrid: Aguilar.

Simon, H. \& March, J. (1993). Organizations (Segunda ed.). Cambridge: Blackwell Publishers.

Taylor, F. W. (2000). Principios de la Administración Cientifica. México D.F.: Herrero Hermanos.

Vickers, G. (1995). The Art of Judgement: A Study of Policy Making. Thousand Oaks: Sage Publishers.

Weber, M. (1964). Economía y sociedad (Segunda ed.). México DF: Fondo de Cultura Económica.

Weimer, D. \& Vining, A. (2005). Policy Analysis: Concepts and Practice (Cuarta ed.). Upper Saddle River: Prentice Hall.

Wildavsky, A. \& Pressman, J. (1998). Implementación: cómo grandes expectativas concebidas en Washington se frustran en Oakland. México D.F.: Fondo de Cultura Económica.

Yin, R. (2002). Case Study Research: Design and Methods. Los Angeles: Sage Publishers.

Zahariadis, N. (2007). The Multiple Streams Framework: Structure, Limitations, Prospects. En P. Sabatier, Theories of the policy process ( $2^{\mathrm{a}}$ ed., pp. 65-92). Boulder: Westview Press. 


\section{MATERIALES CONSULTADOS Y ENTREVISTAS:}

Gobierno Municipal de Zapopan (2005-18-octubre). Reglamento en Materia de Informática y Cómputo para el Municipio de Zapopan. Gaceta Municipal, XII(38).

Gobierno Municipal de Zapopan (2010). Estrategia de Modernización 2010. H. Ayuntamiento Constitucional de Zapopan, Presidencia Municipal. Zapopan: Gobierno Municipal de Zapopan.

Gobierno Municipal de Zapopan (2011). Manual para la Calidad de la Organización y los Procedimientos de la Dirección de Sistemas y Telecomunicaciones. Zapopan: Oficialía Mayor Administrativa.

Gobierno Municipal de Zapopan (2011). Reglamento Interno del Ayuntamiento y la Administración Pública Municipal de Zapopan Jalisco. Gaceta Municipal, XVIII(103).

Herrera, R. (2011-16-diciembre). Entrevista a Asesor de Informática. (Entrevistador) Zapopan, Jalisco, México.

Martínez, Y. (2011-16-12). Entrevista a Directora de Telecomunicaciones y Sistemas del Municipio de Zapopan. (Entrevistador) Zapopan, Jalisco, México. 